\title{
Refocusing Habitat Fragmentation Research Using Lessons from the Last Decade
}

\author{
Adam S. Hadley ${ }^{1,2}$ • Matthew G. Betts ${ }^{2}$
}

Published online: 13 June 2016

(C) Springer International Publishing AG 2016

\begin{abstract}
Habitat alteration is broadly thought to be a primary threat to global biodiversity and has become the dominant topic for conservation biology. However, it is a complex process typically resulting in concurrent loss and increased fragmentation of remaining habitat. Researchers traditionally combined both these processes under a single umbrella term, 'habitat fragmentation', but this practice has ignited a contentious debate since the early 2000s. Over a decade has now past since the emergence of arguments that conservation insight could only be gained by considering loss and fragmentation as independent processes. We examine habitat fragmentation research since these calls for change, and assess the degree to which testing the independent effects of habitat loss and configuration on biodiversity has occurred in the scientific literature. We have found that only modest progress has been made toward this goal (i.e., $18 \%$ of studies) and the majority of researchers continue to treat habitat loss and fragmentation as a single indistinguishable process. We argue that use of
\end{abstract}

Edited and sent for peer review by Dr. Lenore Fahrig, Carleton University.

This article is part of the Topical Collection on Effects of Landscape Structure on Conservation of Species and Biodiversity

Electronic supplementary material The online version of this article (doi:10.1007/s40823-016-0007-8) contains supplementary material, which is available to authorized users.

Adam S. Hadley

hadley.adam@gmail.com

1 Department of Ecology and Evolutionary Biology, University of Toronto, Mississauga, Ontario, Canada L5L1C6

2 Forest Biodiversity Research Network, Department of Forest Ecosystems and Society, Oregon State University, Corvallis, OR 97331, USA consistent definitions and approaches to uncovering specific fragmentation effects is particularly relevant in an era of accelerated human encroachment on natural habitats. Rigorous science on the response by biodiversity to the independent effects of habitat loss and fragmentation provides policy makers with the opportunity to optimize conservation planning efforts. We provide guidelines for how sampling designs and analyses can overcome existing challenges and researchers can search for generality in responses of biodiversity to habitat fragmentation.

Keywords Habitat fragmentation $\cdot$ Habitat loss $\cdot$ Landscape composition $\cdot$ Landscape configuration $\cdot$ Landscape change Independent effects $\cdot$ Biodiversity

\section{Introduction}

With an ever-growing portion of the earth's surface exploited for human use (50-70\% [1]), there is an intensifying demand for clear policy and research focus on habitat alteration [2]. Theory has long recognized that changes in composition (i.e., the relative amount of different vegetation types or habitats) and landscape configuration (i.e., the spatial patterning of different vegetation types) can be thought of as driving separate ecological processes - which in turn, influence biodiversity in different ways [3, 4]. Habitat loss refers to changes in landscape composition, whereas habitat fragmentation per se is the breaking apart of habitat [5]. However, a key problem faced by landscape ecologists is that under most types of anthropogenic resource exploitation, changes in landscape-scale vegetation composition and configuration occur simultaneously [6-8]. For instance, if a road is developed through jungle, the forest is fragmented into smaller patches, but habitat is simultaneously lost due to both the road and adjacent forest harvesting. As a result, applied research in landscape ecology has historically 
struggled with the concepts of habitat loss and fragmentation; researchers tend to use highly variable terminology and commonly lump the combined effects of the two processes under a single umbrella term 'habitat fragmentation' [8].

In a landmark 2003 review [5], Fahrig challenged this practice by pointing out that 'fragmentation' implies more than simply habitat removal and the term inherently suggests an additional change in the pattern of the remaining habitat. Her review suggested that removal of habitat and changes in habitat pattern do not necessarily have consistent effects on biodiversity and that the natural confounding of changes in composition and configuration has resulted in a substantial body of research unable to distinguish between the effects of habitat loss, and those of fragmentation per se [5,9]. She recommended that studying the effects of land-use changes could be streamlined by considering the process of removing habitat to be 'habitat loss' and reserving the term 'habitat fragmentation' for the breaking apart of habitat independent of habitat loss.

In this article, we review the literature to examine how habitat fragmentation research has developed in response to recommendations of Fahrig's [5] highly cited review (cited 2105 times; ISI Web of Knowledge, 7 January 7 2016). We assess the rate at which researchers have adopted the concept of treating habitat loss and habitat fragmentation as separate processes; given the high citation impact of the review, we considered it a plausible hypothesis that the proportion of work employing this approach should have increased over the past decade. We also examine arguments that authors have used for not distinguishing between these processes. Finally, we identify five opportunities for refining future work on habitat loss and fragmentation.

\section{Status of Habitat Fragmentation Research}

Habitat fragmentation continues to be a high-profile topic in biodiversity conservation $[10,11]$, which is not surprising, given the rapid pace of this process globally. For example, $70 \%$ of the world's remaining forest is within $1 \mathrm{~km}$ of an anthropogenic edge [11]. In 2003, 313 papers were published that contained the term 'habitat AND fragmentation', and this body of work has grown substantially, with 706 papers containing the term habitat fragmentation published during 2014 (Fig. 1; Topic="habitat AND fragmentation", ISI Web of Science database). To examine current research progress, we conducted a search of the ISI Web of Science database. We searched for articles containing specific key words in their title commonly associated with habitat fragmentation research (Title = ["habitat fragmentation" or "landscape fragmentation" or "forest fragmentation" or "habitat loss" or "landscape loss" or "forest loss" or "landscape composition" or "landscape configuration" or "habitat composition" or "habitat configuration" or "forest composition" or "forest configuration" or

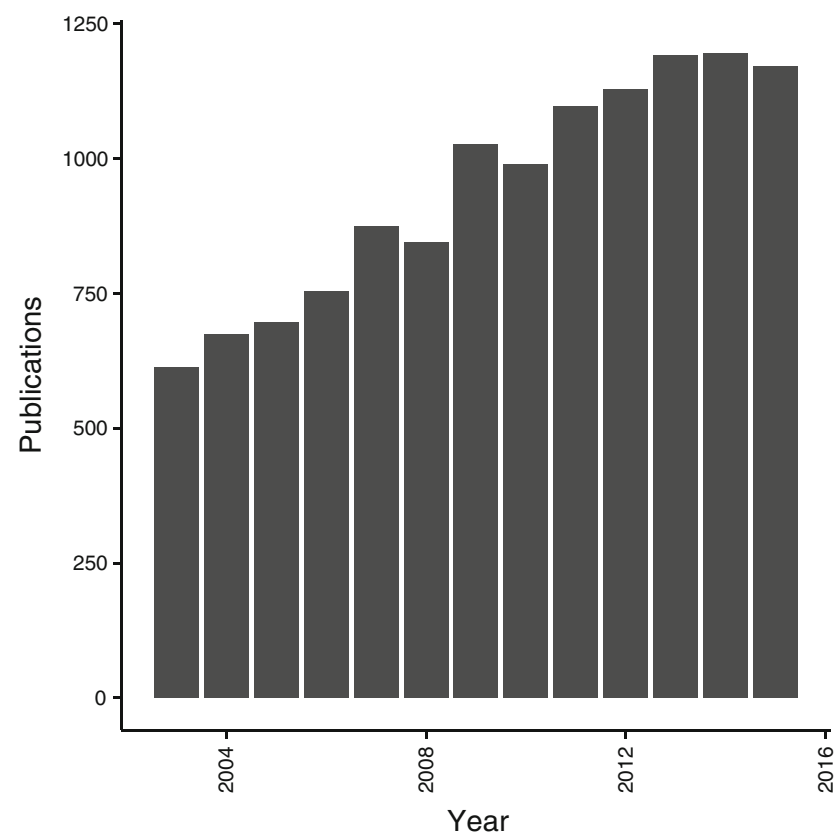

Fig. 1 The number of publications per year on the subject of habitat fragmentation has nearly doubled since 2003. All publications including "habitat AND fragmentation" within an ISI Web of Science database topic search are listed by year

"habitat patch size" or "landscape patch size" or "forest patch size" or "habitat connectivity" or "landscape connectivity" or "forest connectivity" or "habitat isolation" or "landscape isolation" or "forest isolation" or "edge effects"], Timespan $=2004-2015$, Databases $=$ SCI-Extended, SSCI. Date of search $=4$ September 2015). We included "occupancy" or "abundance" or "occurrence" as subject area options to focus on common empirical biodiversity responses. This resulted in 685 articles. From these, we randomly selected 100 articles stratified across years (i.e., the number of papers randomly selected from each year was proportional to the percentage that year represented of the total sample). To be included in the sample, an article needed to contain the term "fragmentation" within the text and examine an effect of landscape composition or configuration on an aspect of biodiversity. If an article did not meet these criteria, we randomly selected a replacement article from the same year. This data set thus represents an unbiased sample of the existing literature on habitat fragmentation.

We examined each of these articles in detail to extract information on the following questions relating to key recommendations made in Fahrig's 2003 paper: 1. a) Do the authors define what they are referring to as habitat fragmentation? b) Do the authors consider habitat fragmentation to be 'the breaking apart of habitat independent of amount' or 'the combined processes of habitat loss and changes in configuration?' 2. Do the authors control for effects of habitat loss either through sampling design or statistically before interpreting the remaining variance attributable to habitat fragmentation? 
We examined how the frequency of articles addressing each of these points changed over time and if articles citing Fahrig 2003 were more likely to have followed her recommendations.

\section{Habitat Loss and Fragmentation as Separate Concepts}

A key way to provide policy makers with useful advice on landscape design is to determine if altering the spatial pattern of landscape cover can substantially reduce human impacts to biodiversity [12]. Can the direct manipulation of the spatial configuration of landscapes (i.e., altering fragmentation per se) through land-use planning ameliorate the negative effects of habitat loss [13]? Or alternatively, are such efforts a waste of conservation money and effort? This issue is critical because humanity's current capacity for protecting land from development is severely limited [14-16].

We found that $18 \%$ of the studies in our sample controlled for the effects of habitat amount when investigating habitat fragmentation (Supporting online material Table S1). Two of these 18 studies were modeling based and 16 studies were empirical. Four of these controlled for habitat amount experimentally, five through mensurative sampling designs, and 12 used statistical approaches (some studies used multiple methods).

Prior to 2003, only 17 studies were known to have controlled for the effects of habitat loss when examining habitat fragmentation [5] and in a sample of 100 articles, containing "habitat fragmentation", "forest fragmentation" or "landscape fragmentation" in the title, Fahrig found no studies that separated composition from configuration (see [5] for details). Our findings suggest that while there has been a modest shift within the field of landscape ecology since [5], it remains relatively uncommon (Fig. 2). Treating habitat loss and fragmentation as a single process is apparently still the norm in landscape ecology research. Further, there is apparently no trend toward increased separation of fragmentation effects from habitat loss over time. Figure 2; (logistic regression: $\hat{\beta}=0.013 \pm 0.011,[\hat{\beta} \pm \mathrm{SE}], P=0.271)$. In some respects, it is reassuring that papers citing Fahrig 2003 were 1.3 times more likely to consider habitat loss and habitat fragmentation as separate processes when designing their studies (logistic regression: $\hat{\beta}=0.30$ $\pm 0.076,[\hat{\beta} \pm \mathrm{SE}], p<0.001)$; however, this still leaves $65 \%$ of articles citing Fahrig that subsequently confounded these processes in their analysis. In summary, it is clear that distinguishing habitat loss from fragmentation is far from being the dominant paradigm in the landscape ecological literature.

\section{Why is Research Separating Habitat Loss from Fragmentation Still Uncommon and Why Should It Be More Common?}

Below we consider several arguments that have been made for ignoring the need to separate the effects of habitat loss and fragmentation. We then present counter-points that should be considered by researchers prior to dismissing the value of disentangling these processes.

\section{Argument that Distinguishing these Processes Is Unimportant}

One possible explanation for the apparent reluctance to separate habitat loss from fragmentation effects is that some researchers remain unconvinced that this distinction is important. Our data certainly support this hypothesis. We found that despite the ambiguous meanings associated with the term 'habitat fragmentation', most researchers do not define it (Fig. 2). Fifty-two percent of the articles we examined did not provide any definition, but rather treated habitat fragmentation as a process whose meaning was sufficiently broadly understood that it required no specific explanation. Of those providing a definition, $60 \%$ considered habitat fragmentation to be an umbrella term for both habitat loss and changes in configuration, while only $40 \%$ considered habitat fragmentation to be changes in configuration independent of habitat amount. Researchers who provided a definition for habitat fragmentation as an independent process were 1.54 times more likely to design studies that allowed separate effects of habitat loss and fragmentation to be considered (logistic regression: $\hat{\beta}=0.43 \pm 0.09,[\hat{\beta} \pm \mathrm{SE}], p<0.001)$, which suggests that the authors of the articles lacking specific definitions of fragmentation and loss may not be convinced that such a distinction is warranted or relevant. Indeed, the notion that fragmentation and habitat loss are important as distinct concepts has recently been challenged on grounds that it presents a false dichotomy that is not useful in landscape ecology; habitat loss and fragmentation typically occur together and have interdependent effects $[17,18]$.

However, we argue that the primary motivations for distinguishing habitat loss from fragmentation are no less relevant than they were more than a decade ago. First, uncovering the relative importance of these factors provides insight about the mechanisms driving the effects of landscape changes on biodiversity. If organisms respond differently to changes in composition versus configuration, then considering habitat loss and habitat fragmentation as separate processes is a valuable tool for both understanding and predicting biodiversity responses.

Theory predicts that landscape configuration should have additional impacts on biodiversity beyond those of habitat loss alone [19]. However, empirical evidence for the relative 
Fig. 2 a) The yearly proportion of the 100 articles within our stratified random sample of habitat fragmentation research that separate effects of composition from configuration. We found that only $18 \%$ of articles within the total sample of 100 controlled for habitat amount when considering effects of fragmentation. b) The yearly proportion of articles defining habitat fragmentation. We found less than half of the papers within the sample provided a definition for what they considered to be habitat fragmentation. c) The proportion of articles within the sample citing Fahrig 2003 in each year

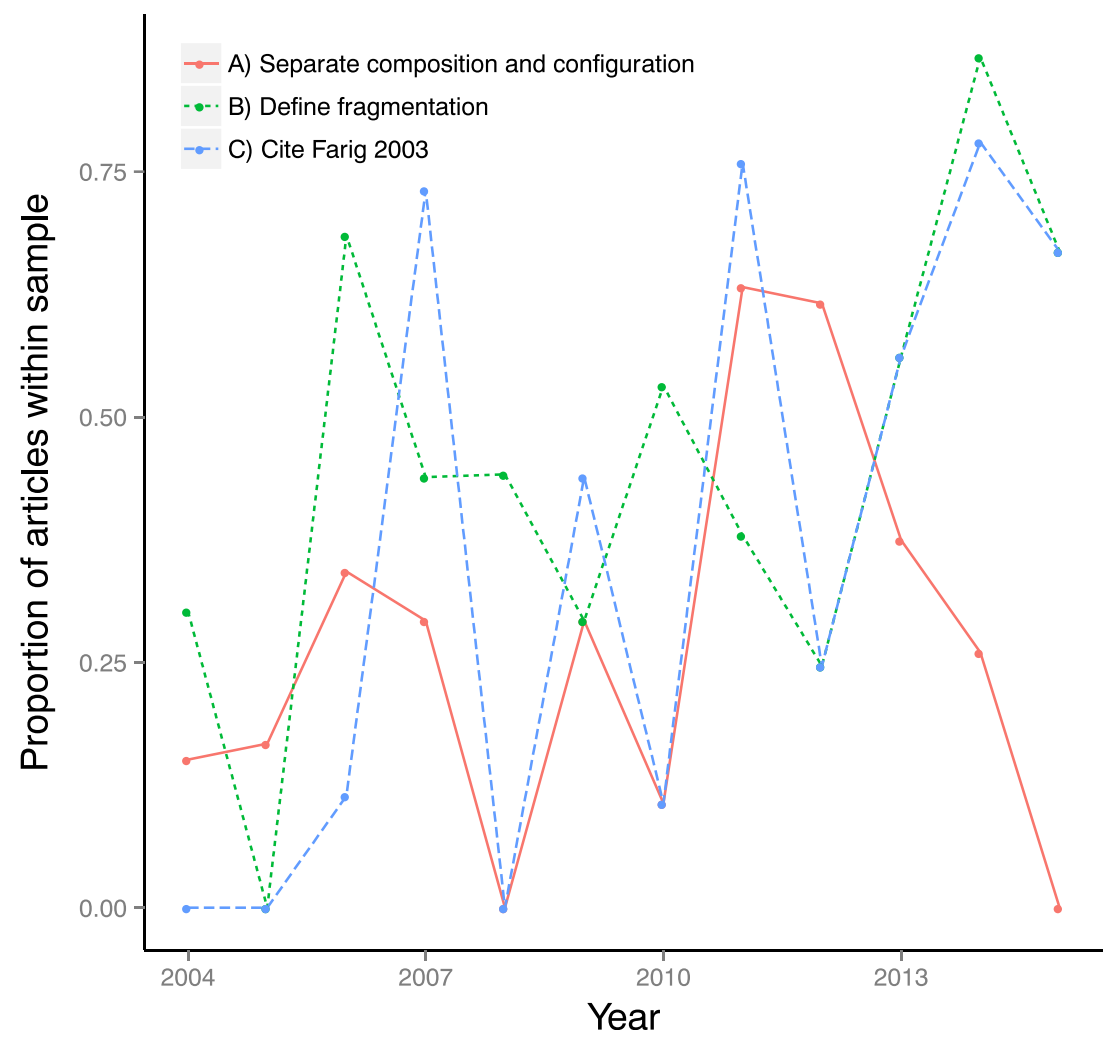

importance of habitat loss versus habitat fragmentation on biodiversity is still mixed [20]. Habitat fragmentation per se is expected to have independent effects on biodiversity via changes in landscape configuration due to patch size, edge, and landscape connectivity. These independent fragmentation effects are likely to act via a number of mechanisms, but these can primarily be summarized as differences in habitat quality next to edges and movement- or dispersal-related effects [see 21 for a detailed discussion]. For example, if after accounting for habitat amount, structural connectivity (a configuration variable) is the strongest predictor of species richness, abundance or occurrence, we can infer that movement limitation is a likely driver of these processes [e.g., 22, 23]. On the other hand, if habitat amount at landscape scales is the primary explanatory variable, it could be argued that colonization rates of species in that system are more driven by the abundance of propagules in the surrounding area [i.e., a mass effect; 24].

Evidence for independent effects of fragmentation is accumulating. Of the 16 empirical studies within our sample that separate effects of habitat amount prior to examining fragmentation, the majority (15/16 empirical studies) found changes in landscape configuration to have important independent effects even after controlling for landscape composition. These included negative effects of reducing patch sizes [25-27], increasing inter-patch distances [28-30], and proximity to edges $[31,32]$. However, it is important to note that independent effects of fragmentation in this sample were not always negative; some studies documented positive effects of habitat fragmentation after controlling for habitat amount. For instance, Bonin et al. [33] found positive effects of increasing patch densities, and Yamaura and Katoh [34] found positive effects of patch elongation. Further, some studies even documented both positive and negative effects of fragmentation within the same landscape depending on the biological response of interest $[25,30,35]$. These results suggest that separating components of habitat loss from fragmentation often reveals additional insight into the mechanisms underlying biodiversity responses to landscape changes that would be masked when the two processes are considered together.

\section{Challenges of Study Design Argument}

A second hypothesis, for researchers being slow to adopt habitat loss and fragmentation as separate processes, could relate to challenges associated with particular study systems. For example, in situations where there is little political capacity to bring about conservation changes (e.g., private lands) or little capacity to alter the existing landscape (e.g., heavily urbanized landscapes or other long-term alterations), there may be little conservation value in studies that separate effects of habitat loss and fragmentation. Therefore, incentive to conduct such research may be reduced in systems where changes to landscape pattern seem unlikely. Similarly, landscapes with long histories of habitat alteration [36] may have reached relatively stable states where conservation managers see little opportunity for adaptive management; habitat destruction in 
these 'static' landscapes may have ceased, but there may also be little capacity for restoration due to historical land-use designations and land tenure. Finally, even in dynamic landscapes with continued habitat alteration, researchers may feel that separating habitat loss from habitat fragmentation is logistically infeasible due to natural confounding within study landscapes [37].

In response to this, we emphasize that independent control of these factors is possible via active management of landscapes. Given that $30-50 \%$ of the earth's productive land surface is now exploited for human needs $[1,38]$, this is not a trivial point. In dynamic forested and agricultural landscapes patches, linear connections and matrix can be created or destroyed via management over short time periods (Fig. 3). Therefore, humans have the capacity to independently vary habitat loss/addition and fragmentation by developing policies that strongly emphasize either landscape composition, landscape configuration or both [39]. Precedence exists for this across multiple continents and systems [40-49], with notable examples including large international corridor projects (e.g.,

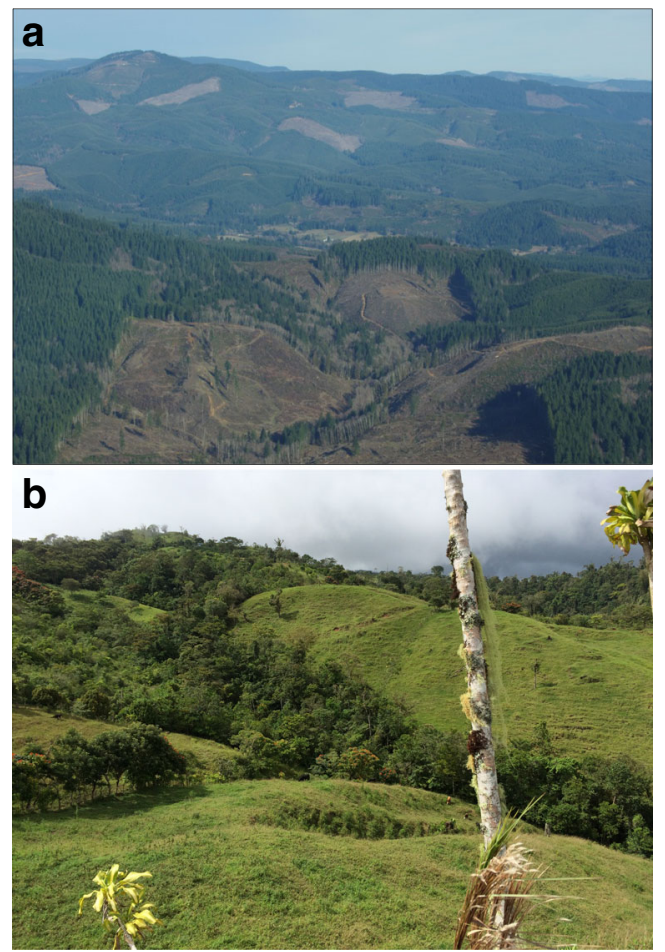

Fig. 3 a) An intensively managed forest landscape in western Oregon. b) An example of a heterogeneous tropical landscape with living fencerows and riparian corridors in southern Costa Rica. These represent examples of dynamic landscapes where managers and policy makers have considerable latitude to affect the spatial configuration (fragmentation) of a landscape via alternative practices. In such instances, it is critical to distinguish the effects of habitat loss from fragmentation; if fragmentation has a negative influence on biodiversity over and above the effect of habitat loss, managers could potentially redesign landscapes to ameliorate such impacts. For example, in (b), narrow connecting elements can be restored with relatively little area cost [photo credit: (a) Matthew Betts, Oregon State University; (b) Sarah Frey, Oregon State University]
[43]) and the Northwest Forest Service Plan [40], which influences landscape pattern across three states within the Western U.S.. The demand for recommendations on how to strategically alter landscape composition and configuration is continuing to grow, as is the capacity to actively do so [42, 50-54]; there are 15 major international restoration initiatives that have optimizing landscape configuration as a primary goal [55], and altering the configuration of native habitat within agricultural landscapes is central to efficiently optimizing ecosystem processes [56] and services [57].

It is therefore important to discern the degree to which fragmentation and habitat loss matter, because these managers and policy makers have the capacity to alter the configuration of landscapes while maintaining set amounts of key land cover types. For example, a given area of forest can be harvested in a simple pattern of large cut-blocks or in a complex pattern of smaller, irregularly shaped clearings [58] and this may have profound effects on individual species and key ecosystem processes [21, 59]. Similarly, corridors can be maintained or hedgerows restored to enhance ecosystem functions such as pollination $[56,60]$. Small patches are kept at the expense of large ones if ecosystem representativeness is the goal [61]; alternatively, large patches can be maintained with the goal of reducing local extinction probability [62].

\section{How can Researchers Separate the Independent Components of Habitat Loss and Habitat Fragmentation Effects on Biodiversity?}

\section{Experimental Landscapes}

The gold standard for separating effects of landscape composition and configuration is through experimental landscapes where composition and configuration are manipulated in a controlled, replicated fashion. These experiments have revealed strong support for the independent effects of composition and configuration across various taxa, systems and processes (e.g., [31, 63, 64]). We strongly support the continued need for additional landscape experiments [10,11], particularly within late successional land-cover types. However, the scale(s) of few studies approach those at which contemporary conservation management decisions take place, and widespread adoption of this experimental approach is unrealistic due to a number of logistical challenges [10]. First, the demands of replication typically lock an experiment into examining one or two specific landscape processes. This is particularly true of large-scale experiments that are typically designed to understand very specific questions such as the importance of corridors [23] or patch area/edges [65]. Similarly, designing experimental studies so that they consider configuration effects at multiple spatial scales is a substantial challenge. Clearly, intimate knowledge of the focal system is 
critical for selecting the most appropriate scale, but what if configuration effects prevail across scales, or at different scales depending on the species and/or process of interest? Third, experiments are often expensive and can require formidable challenges to gain co-operation from various stakeholders [66]. Finally, it can take years before the full effects of landscape changes are accrued [65].

\section{Mensurative Experiments}

'Mensurative experiments', where the deliberate choice of sampling space is the 'experimental variable' [67], are another approach for separating the independent effects of habitat loss and habitat fragmentation using strategic sampling designs. Random stratified sampling designs can be used to substantially reduce the confounding of composition and configuration within a wide range of natural landscapes [e.g., 6, 68, 69]. While not providing the same strong inference as direct landscape manipulation [70], these sampling designs can be employed a priori using spatial data on land cover to provide substantial decoupling of composition and configuration even in highly correlated landscape contexts. Such designs can be very efficient, since no direct landscape manipulation is necessary and therefore a large number of sites can be examined. However, as with manipulative experiments, it can become challenging to stratify across multiple landscape variables [69], which can limit the number of variables that can be decoupled.

While the idea of finding existing landscapes that differ along these gradients may seem challenging, it can be accomplished relatively efficiently via a 'focal landscape' or 'local landscape' approach - where the context of a sampling site (e.g., habitat amount etc.) is considered within an ecologically relevant surrounding distance [20] and sampling effort can be stratified to vary composition and configuration variables independently [69]. Within our sample, the studies that controlled for loss while looking at habitat fragmentation typically used this approach (12/16 empirical studies).

\section{Statistical Control}

Various statistical approaches have been used to disentangle the effects of habitat loss and fragmentation and their effectiveness at confronting collinearity was assessed in a review by Smith et al. [71]. In this simulation experiment, standard multiple regression performed as well or better than all of the other methods that have been used to account for collinearity [71]. Partial regression coefficients were unbiased for influential predictors even when the predictors were highly correlated. Researchers can also examine indirect effects within a multiple regression framework by testing for interactions between configuration and composition predictors to determine if effects of habitat fragmentation are expected to vary depending on habitat amount $[68,72]$. Recently, path analysis has been suggested as an alternative method to reliably identify the causal basis of collinearity and give estimates of direct, indirect and total effects of confounded habitat loss and fragmentation metrics [73].

Regardless of the choice of statistical method, studies will have more statistical power if sampling designs are constructed in a way that minimizes the confounding of variables [e.g., through use of manipulative or mensurative experiments; 74]. The risk of embracing as inevitable the natural intercorrelation of landscape variables [18] and relying solely on statistical control is that, under non-experimental conditions, a researcher will end up with a high degree of confounding [5]; when variables are confounded, scientists are forced to shrug and, regardless of the power of the statistical methods used, little light can be shed on likely mechanisms for the landscape effects uncovered. Consider a hypothetical instance in which research on cougar movement has been poorly designed such that a configuration variable, the presence of vegetation cover that connects patches of native forest, is confounded with the total amount of native forest cover. The conclusion of the study is that variability in the movement of cougars is partitioned among configuration (5\%), the amount of forest cover (5\%), variation shared between configuration and the amount of forest cover $(60 \%)$ and unexplained variation (30\%) (Fig. 4). What does a policy maker with a limited budget do? He/she might gamble that a high proportion of the shared variation is actually due to configuration, and design a landscape that has $5 \%$ native forest cover remaining but is highly connected through expensive land acquisition for corridors. Alternatively, he or she might gamble the reverse; that the amount of forest cover is driving the shared component and therefore buy the least expensive areas of native forest irrespective of configuration, resulting in more forest in the landscape (e.g., $20 \%$ ). If the shared variation is in fact due mainly to the effects of forest amount, the conservation outcome in the first case may be poor, whereas if the shared variation is mainly due to the effects of connectivity, the conservation outcome in the second case will be poor. This is a dangerous game, because inefficient outcomes for expensive conservation actions reduce the likelihood of implementation of future conservation actions [75].

\section{Five Key Opportunities for How the Study of Habitat Fragmentation Can Continue to Yield Conservation Relevant Information}

\section{Separating Effects of Habitat Loss from Those of Configuration}

Biodiversity can potentially respond to both changes in landscape configuration and landscape composition. Therefore, 


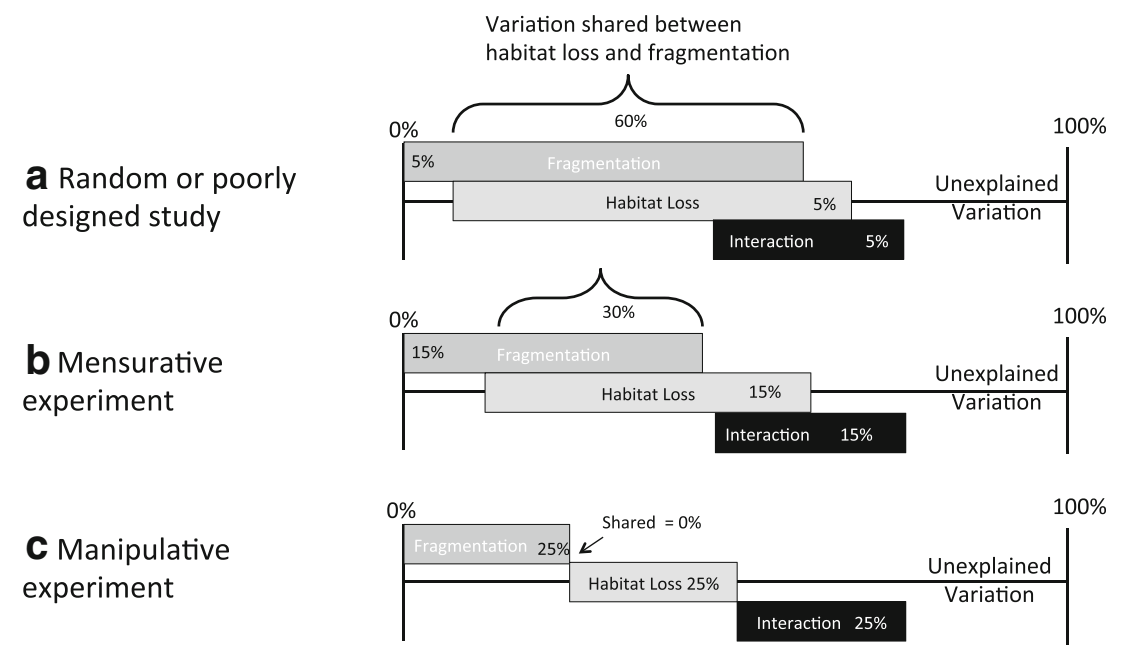

Fig. 4 Variance partitioning for the hypothetical response of biodiversity to habitat loss versus fragmentation under three scenarios: (a) a study that has been designed with completely random or haphazard sampling in which habitat loss is very likely to be confounded with fragmentation yielding equivocal results, (b) a mensurative experiment where

we reiterate the frequent recommendations that the relative importance of various processes of landscape change be evaluated $[5,8,12,20,21,73]$. We recommend that whenever possible, researchers design their studies to limit the natural confounding of habitat loss and fragmentation and/or use statistical approaches that allow for separation $[71,73]$. This will increase researchers' ability to provide accurate management and policy relevant recommendations.

\section{Clear Terminology}

Clearly, the field of landscape ecology continues to struggle in search of appropriate terminology. We found that it is still uncommon for researchers to provide any form of definition for 'fragmentation', and definitions provided almost equally refer to the combined processes of habitat loss and fragmentation as to the more specific breaking apart of habitat per se. This tendency toward inconsistent and ambiguous terminology is certainly not new in landscape ecology [5] or other fields of ecology [76]. Lindenmayer and Fisher (2007) tackled these issues and suggested options for how landscape ecologists could adopt unambiguous terminology (See Lindenmayer and Fisher [2007; Table 1] for useful definitions of key themes associated with landscape change). They highlight some unfortunate consequences of vague and inconsistent terminology in habitat fragmentation research. Identifying key threatening processes is fundamental to devising strategies to mitigate those effects, and if the term 'habitat fragmentation' is used in too many ways, it becomes useless as a theory or explanation for effects [8].

We submit that definitions should be based on the major elements of landscape structure: composition and configuration researchers have stratified sampling across existing landscapes to reduce confounding between habitat loss and fragmentation, (c) a manipulative experiment where fragmentation and habitat loss are orthogonal. The last two approaches will yield results more relevant to policy makers on landscape design for biodiversity conservation

[4]. Using these general terms and then clearly describing the particular aspects under consideration has the following benefits to science and policy communication. First, unlike habitat loss and fragmentation, changes in landscape composition and configuration are not inherently directional. This provides greater flexibility for encompassing the complexity within real-world landscapes in which regeneration and loss may be occurring simultaneously [77]. Secondly, landscape composition and configuration avoid the complications relating to definitions of 'habitat' since there is no implication that the researcher is using species-centered or continuum habitat views [78]. This provides greater flexibility for accommodating both 'species-centered habitat' $[8,78]$ and 'integrated community' [18] views within the same nomenclature. Finally, landscape composition and landscape configuration have been used relatively sparingly, which reduces the danger of researchers viewing them as being 'known entities'. For example, while it might currently seem trivial and superfluous for each manuscript to define habitat loss and fragmentation, it would be natural for authors to define the specific aspects of landscapes they are examining within the more general themes of composition and configuration.

When authors wish to use habitat loss and fragmentation to refer to landscape changes, we repeat the call $[5,8,12]$ for habitat loss to be defined as the removal of habitat or native land cover and used only for changes in composition. Habitat fragmentation, on the other hand, should be reserved for changes in configuration that result from the breaking apart of habitat independent of habitat loss. If 'habitat fragmentation' is to continue as a useful concept, it should not be used for anything other than changes in landscape configuration [8]. In instances where researchers are searching for a single 
'umbrella term' to refer to combined processes of landscape change (e.g., research efforts that focus on habitat loss and fragmentation as a single interdependent process), we recommend using a broad term such as 'habitat alteration' [79], 'habitat destruction' [11], or 'landscape change' [80]. Alternatively, it is perfectly acceptable for a researcher to simply refer to their results as reflecting the 'combined effects of habitat loss and fragmentation'.

\section{Habitat Definitions}

One hypothesis for why so few studies have documented fragmentation effects [5] relates to the potential for inaccurately measuring habitat [78]. The terms habitat loss and habitat fragmentation imply changes in the habitat availability for species. However, anthropogenic 'habitat' designations such as vegetation composition categories are unlikely to represent true habitat differences perceived by organisms. We found that within our sample only $2 \%$ of studies actually quantify 'habitat per se', but rather habitat continues to be typically used as loosely equivalent to native vegetation [8]. We suggest that researchers should specify if the focus of the work is on either anthropogenic designations of patterns in land-cover (e.g., amount or configuration of vegetation) or on patterns of habitat suitability for a particular individual species [e.g., 68, 69, 81]. Recent work has suggested that use of land cover changes instead of actual habitat suitability may be resulting in some of the inconsistencies seen regarding responses of biodiversity to landscape change $[78,82]$. Species distribution models (SDMs) [83] can be used to measure landscapes (e. g., patch size, isolation, matrix amount) from the perspective of individual species, and once differences in habitat distributions are considered, consistencies in species' responses to landscape structure emerge [78]. Such approaches may be particularly challenging to implement in community level studies [20]. However, recent statistical modeling approaches (e.g., stacked species distribution models; [84]) and advances in freely available land-cover data mean that this speciescentered approach may be scaled up to test hypotheses about the effects of landscape composition and configuration on community assembly [85].

\section{The Importance of Equivalent Scale in Considering the Effects of Habitat Loss and Fragmentation}

In her 2003 review, Fahrig found little evidence for independent effects of habitat fragmentation above those of loss. To some extent, the finding that habitat loss results in population decline is nearly trivial. The consistent negative trend across studies with local habitat removal is unsurprising, given that the species cannot occur at sites that are no longer suitable habitat. Of interest to landscape planners, theoreticians and empiricists is the degree to which the amount of habitat in the surrounding landscape versus the habitat pattern influences biodiversity. Thus, issues of scale are extremely important in understanding the relative impact of habitat loss and fragmentation. In the process of habitat loss from intact landscapes (Figs. 5a and 6a), minor habitat reductions most likely result in proportionate declines in the number of animals able to persist in a given landscape. This has been termed the random sample hypothesis [3] (Fig. 6b). The second component of habitat loss lies in changes in landscape composition

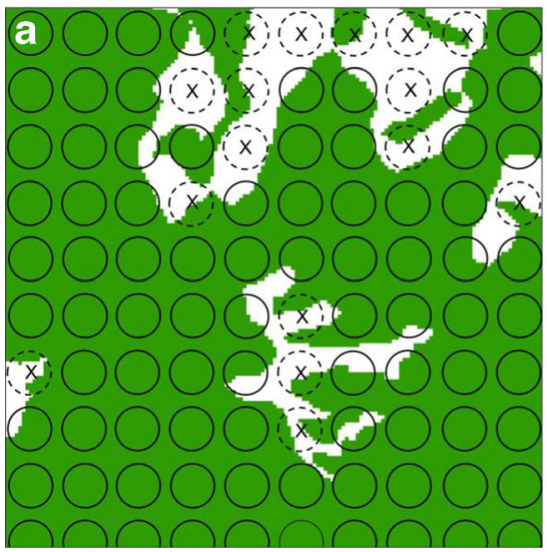

Fig. 5 Habitat loss can affect organisms at different scales. a) Local-scale habitat loss or loss of habitat at the site where an organism lives will result in animals being unable to persist at that particular location. This 'local scale' reflects species-specific habitat requirements and matches the scale of a single animal or breeding pair's territory. In this example the species requires at least $50 \%$ of its home range to be suitable habitat shown in green. The solid black circles represent hypothetical home ranges and the dashed circles represent locations where insufficient habitat remains within the home range boundary to support an individual. b) The

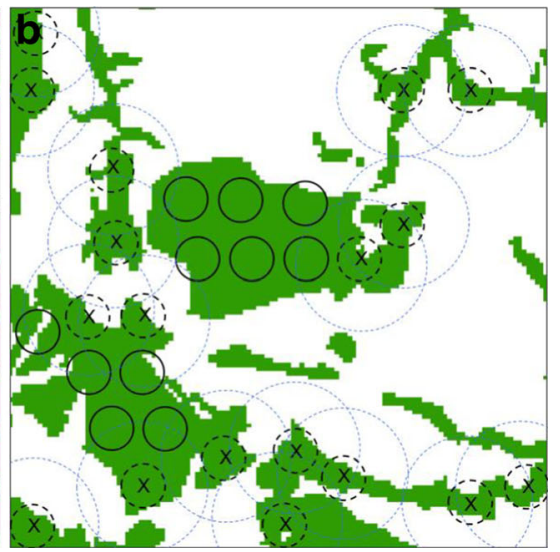

second component of habitat loss lies in landscape composition changes surrounding suitable sites (i.e., beyond the scale of an individual territory or home range). In this example, the species also requires $50 \%$ of the surrounding landscape within two times the diameter of its home range to be suitable habitat. The dashed black circles in panel (b) show locations where habitat is locally suitable, but the sites are unoccupied since they have insufficient habitat within the surrounding landscape (represented by light blue dashed lines) 


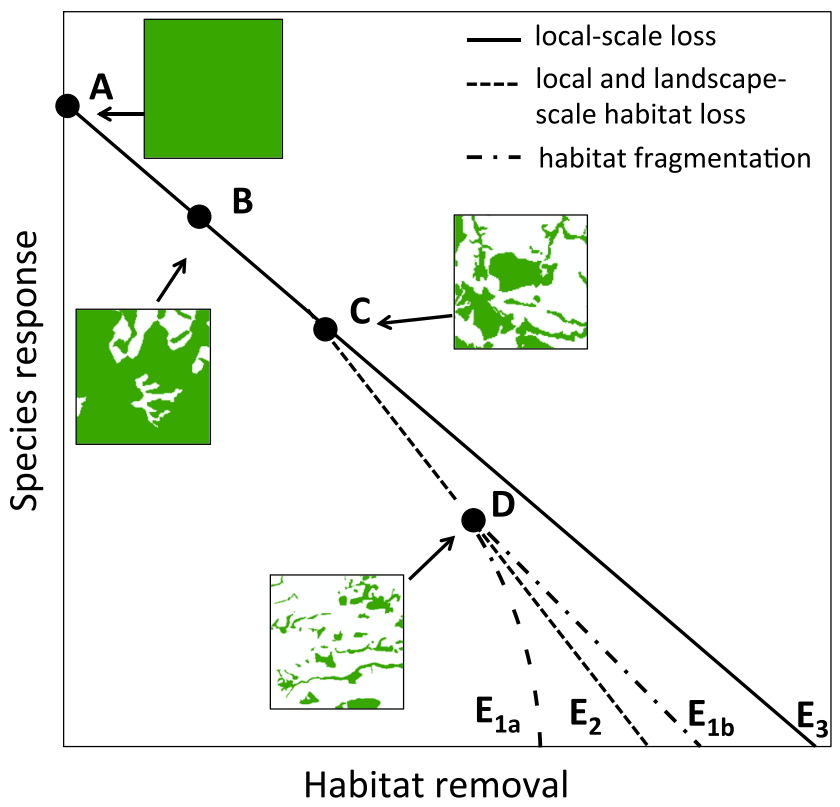

Fig. 6 Three main aspects of landscape change (i.e., local-scale habitat loss, landscape-scale habitat loss, and habitat fragmentation) can affect species distributions and demography. a) The intact landscape prior to any changes. b) The effect of "local-scale habitat loss". In this instance, habitat loss results in a proportionate decrease in the number of animal territories. c) Shows how landscape-scale habitat (i.e., changes in the landscape composition surrounding the site) can have additional affects on species, represented by the dashed line. For example, loss of habitat in the surrounding landscape can decrease the probability of colonization for a site (i.e., a "mass effect"). d) The effects of habitat fragmentation (i.e., changes in configuration of the surrounding landscape) can also affect species (e.g., gap-crossing avoidance could reduce inter-patch movement) (shown by the dot-dash line). These three aspects of landscape change each result in separate hypotheses for how species can respond. E1) The "fragmentation threshold" where landscape configuration becomes increasingly important at lower levels of remaining habitat. Landscape configuration can either accentuate (E1a) or mediate effects of loss (E1b). E2) The "mass effect" or "habitat amount hypothesis" stems from changes in composition at scales beyond individual locations or home ranges. E3) The "random sample hypothesis" where species response is directly proportional to area lost. Each of these hypotheses results in a different trajectory of species responses to landscape changes. Habitat is shown in green

surrounding suitable sites (i.e., beyond the scale of an individual territory or home range) (Figs. 5b and 6c). At this broader landscape scale, habitat loss also has the potential to reduce population size due to reduced colonization [86], limited opportunities for extra pair mating [87] and reduced possibilities for patch supplementation [88]. The final aspect of landscape change has to do with the landscape configuration or the spatial pattern of remaining habitat within the landscape (Fig. 6d). Theory predicts that such fragmentation effects should occur primarily when the total amount of habitat in a landscape is low [89], but see Ref. [12]. These three possibilities form alternative hypotheses, each with testable predictions about the relationship between habitat loss and population decline [68].
Unfortunately, effects of local and landscape scale habitat loss are often considered simultaneously, which makes it difficult to determine the relative role of scale in habitat amount versus fragmentation effects. Such studies obscure the potential mechanism (i.e., predictable site-level habitat change, versus landscape-scale mass effects). Only $13 \%$ of the articles we examined controlled for local habitat quality when considering landscape-scale processes. We suggest that for landscape ecology to move toward greater generality, it will be important for researchers not only to consider the separate components of habitat loss vs. fragmentation effects, but to also explicitly recognize that spatial scale (i.e., local vs. broader scales) may influence the processes under consideration.

\section{Identifying Critical Thresholds}

In her 2003 article, Fahrig highlighted two hypotheses for how species might show important thresholds in their responses to landscape changes. First, theory predicts that minimum habitat requirements for population persistence (i.e., the extinction threshold) will be influenced by habitat configuration and that these minimum requirements will be higher when configuration impedes functional connectivity [90]. The second hypothesis, known as the fragmentation threshold hypothesis, predicts that effects of configuration are greater at the lower end of the habitat loss gradient $[5,91]$. We found only $1 \%$ of studies within our sample considered thresholds in species responses to land-use changes. Villard and Metzger [12] recently re-emphasized the need for landscape ecologists to test specific predictions relating to these hypotheses: 1 . Extinction thresholds for a given species will vary as a function of habitat configuration, and 2. Configuration should not matter above a certain habitat amount. These predictions can be tested by comparing extinction thresholds across landscapes with differing configuration, and by comparing the effects of configuration at different levels of habitat amount using techniques such as segmented logistic regression [92, 93]. The fragmentation threshold can also be relatively easily tested within a multiple regression framework by looking for interactions between the composition and configuration variables to see if configuration effects differ depending on habitat amount [72]. This knowledge of interactions between habitat loss and fragmentation is essential for identification of opportunities where optimizing landscape configuration might be used to mitigate the negative effects of habitat loss [12]. Therefore, an important area for future development is testing for thresholds that can be used to identify locations on the landscape where conservation gains from altering landscape configuration are likely to be the most beneficial. 


\section{Conclusion}

Need for conservation and policy recommendations to mitigate the effects of land-use change is growing rapidly, but so is the capacity of science to tackle the complexity of the issues involved and to provide relevant findings. Although there has been increasing recognition of the value in considering the separate effects of habitat loss and habitat fragmentation, most studies continue to struggle with how to evaluate the contributions of these processes. As we suggest above, controlling for local versus landscape scale effects on species distributions and abundance, followed by statistical control for composition versus fragmentation effects, offers a viable and straightforward approach. It is important to note that the majority $(15 / 16)$ of the empirical studies in our sample that attempted to evaluate the relative contributions of loss and fragmentation found independent effects of configuration even after controlling for habitat amount. Fragmentation effects were evident in temperate and tropical systems and for multiple taxa. Given the potential for land managers to independently vary composition and configuration through active management, it is critical to know the potential conservation gains of various strategies. Therefore, separating the relative contributions of the two major processes of land-use change is essential for identification of opportunities where optimizing landscape configuration might be used to mitigate the negative effects of habitat loss on biodiversity. Fortunately, recently compiled global data sets on biodiversity responses to landscape change [e.g., 94, 95] combined with developments in high resolution mapping of global land-cover [77] mean that the current capacity for separating the relative effects of habitat loss and fragmentation on biodiversity is unprecedented.

Acknowledgments We thank J. Valente and B. Phalan for helpful comments on the manuscript. This work was supported by a Natural Sciences and Engineering Research Council of Canada postdoctoral fellowship to A.H. and a National Science Foundation grant DEB-1457837 to M.B. and A.H.

Compliance with Ethical Standards This article does not contain any studies with human or animal subjects performed by any of the authors

Conflict of Interest On behalf of all authors, the corresponding author states that there is no conflict of interest.

\section{References}

1. Barnosky AD, Hadly EA, Bascompte J, Berlow EL, Brown JH, Fortelius M, et al. Approaching a state shift in Earth's biosphere. Nature. 2012;486:52-8.

2. Ewers RM, Marsh CJ, Wearn OR. Making statistics biologically relevant in fragmented landscapes. Trends Ecol Evol. 2010;25: 699-704.
3. Haila Y, Hanski IK. Methodology for studying the effect of habitat fragmentation on land birds. Ann Zool Fenn. 1984;21:393-7.

4. Turner MG. Landscape ecology: the effect of pattern on process. Annu Rev Ecol Syst. 1989;20:171-97.

5. Fahrig L. Effects of habitat fragmentation on biodiversity. Annu Rev Ecol Evol Syst. 2003;34:487-515.

6. McGarigal K, McComb WC. Relationships between landscape structure and breeding birds in the Oregon coast range. Ecol Monogr. 1995;65:235-60.

7. Villard MA, Trzcinski MK, Merriam G. Fragmentation effects on forest birds: relative influence of woodland cover and configuration on landscape occupancy. Conserv Biol. 1999;13:774-83.

8. Lindenmayer DB, Fischer J. Tackling the habitat fragmentation panchreston. Trends Ecol Evol. 2007;22:127-32.

9. Haila Y. A conceptual genealogy of fragmentation research: from island biogeography to landscape ecology. Ecol Appl. 2002;12: 321-34.

10. Wilson M, Chen X-Y, Corlett R, Didham R, Ding P, Holt R, et al. Habitat fragmentation and biodiversity conservation: key findings and future challenges. Landsc Ecol. 2015;31:1-9.

11. Haddad NM, Brudvig LA, Clobert J, Davies KF, Gonzalez A, Holt $\mathrm{RD}$, et al. Habitat fragmentation and its lasting impact on Earth's ecosystems. Sci Adv. 2015;1:1-9.

12. Villard MA, Metzger JP. Beyond the fragmentation debate: a conceptual model to predict when habitat configuration really matters. $\mathrm{J}$ Appl Ecol. 2014;51:309-18.

13. Franklin JE, Forman RTT. Creating landscape patterns by forest cutting: ecological consequences and principles. Landsc Ecol. 1987;1:5-18.

14. Margules CR, Pressey RL. Systematic conservation planning. Nature. 2000;405:243-53.

15. Wilson KA, McBride MF, Bode M, Possingham HP. Prioritizing global conservation efforts. Nature. 2006;440:337-40.

16. Butchart SHM, Walpole M, Collen B, van Strien A, Scharlemann JPW, Almond REA, et al. Global biodiversity: indicators of recent declines. Science. 2010;328:1164-8.

17. Ewers RM, Didham RK. Habitat fragmentation: panchreston or paradigm? Trends Ecol Evol. 2007;22:511.

18. Didham RK, Kapos V, Ewers RM. Rethinking the conceptual foundations of habitat fragmentation research. Oikos. 2012;121:161-70.

19. Hanski I. Habitat fragmentation and species richness. J Biogeogr. 2015;42:989-93.

20. Fahrig L. Rethinking patch size and isolation effects: the habitat amount hypothesis. J Biogeogr. 2013;40:1663.

21. Hadley AS, Betts MG. The effects of landscape fragmentation on pollination dynamics: absence of evidence not evidence of absence. Biol Rev. 2012;87:526-44.

22. Tewksbury JJ, Levey DJ, Haddad NM, Sargent S, Orrock JL, Weldon A, et al. Corridors affect plants, animals, and their interactions in fragmented landscapes. Proc Natl Acad Sci U S A. 2002;99:12923-6.

23. Levey DJ, Bolker BM, Tewksbury JJ, Sargent S, Haddad NM. Effects of landscape corridors on seed dispersal by birds. Science. 2005;309:146-8.

24. Fahrig L. Just a hypothesis: a reply to Hanski. J Biogeogr. 2015;42: 993-4.

25. Brosi BJ. The effects of forest fragmentation on euglossine bee communities (Hymenoptera: Apidae: Euglossini). Biol Conserv. 2009; 142:414-23.

26. Skov MW, Hawkins SJ, Volkelt-Igoe M, Pike J, Thompson RC, Doncaster CP. Patchiness in resource distribution mitigates habitat loss: insights from high-shore grazers. Ecosphere. 2011;2:1-17.

27. Thornton DH, Branch LC, Sunquist ME. Response of large galliforms and tinamous (Cracidae, Phasianidae, Tinamidae) to habitat loss and fragmentation in northern Guatemala. Oryx. 2012;46:567-76. 
28. Bucher R, Entling MH. Contrasting effects of habitat fragmentation, population density, and prey availability on body condition of two orb-weaving spiders. Ecol Entomol. 2011;36:680-5.

29. Coudrain V, Herzog F, Entling MH. Effects of Habitat Fragmentation on Abundance, Larval Food and Parasitism of a Spider-Hunting Wasp. PLoS ONE. 2013;8:doi: 10.1371/journal. pone.0059286.

30. Cousins SAO. Plant species richness in midfield islets and road verges - the effect of landscape fragmentation. Biol Conserv. 2006;127:500-9.

31. With KA, Pavuk DM. Direct versus indirect effects of habitat fragmentation on community patterns in experimental landscapes. Oecologia. 2012;170:517-28.

32. Carroll JM, Furman BT, Tettelbach ST, Peterson BJ. Balancing the edge effects budget: bay scallop settlement and loss along a seagrass edge. Ecology. 2012;93:1637-47.

33. Bonin MC, Almany GR, Jones GP. Contrasting effects of habitat loss and fragmentation on coral-associated reef fishes. Ecology. 2011;92:1503-12.

34. Yamaura Y, Katoh K. Effects of deciduous forest loss caused by larch plantation matrix on bird assemblages. Jpn J Ornithol. 2007;56:9-21.

35. Schueepp C, Uzman D, Herzog F, Entling MH. Habitat isolation affects plant-herbivore-enemy interactions on cherry trees. Biol Control. 2014;71:56-64.

36. Watts K. British forest landscapes - the legacy of woodland fragmentation. Q J For. 2006;100:273-9.

37. Ewers RM, Didham RK. Confounding factors in the detection of species responses to habitat fragmentation. Biol Rev. 2005;81:11742.

38. Vitousek PM, Mooney HA, Lubchenco J, Melillo JM. Human domination of Earth's ecosystems. Science. 1997;277:494-9.

39. Fischer J, Brosi B, Daily GC, Ehrlich PR, Goldman R, Goldstein J, et al. Should agricultural policies encourage land sparing or wildlife-friendly farming? Front Ecol Environ. 2008;6:382-7.

40. Thomas JW, Franklin JF, Gordon J, Johnson KN. The northwest forest plan: origins, components, implementation experience, and suggestions for change. Conserv Biol. 2006;20:277-87.

41. Kaiser J. Conservation biology - bold corridor project confronts political reality. Science. 2001;293:2196-9.

42. Brodie JF, Paxton M, Nagulendran K, Balamurugan G, Clements GR, Reynolds $\mathrm{G}$ et al. Connecting science, policy, and implementation for landscape-scale habitat connectivity. Conservation Biology. 2015;Online Early.

43. Locke H, Heuer K. Yellowstone to Yukon: Global Conservation Innovations Through the Years. In: Wuerthner G, Crist E, Butler T, editors. Protecting the Wild. Island Press/Center for Resource Economics; 2015. p. 120-30.

44. Mazaris AD, Papanikolaou AD, Barbet-Massin M, Kallimanis AS, Jiguet F, Schmeller DS, et al. Evaluating the connectivity of a protected areas' network under the prism of global change: the efficiency of the european natura 2000 network for four birds of prey. PloS One. 2013;8, e59640.

45. Pino J, Marull J. Ecological networks: are they enough for connectivity conservation? A case study in the barcelona metropolitan region (NE Spain). Land Use Policy. 2012;29:684-90.

46. Fitzsimons J, Pulsford I, Wescott G. Linking Australia's Landscapes: Lessons and Opportunities from Large-scale Conservation Networks. CSIRO Publishing. 2013.

47. Pinto NN et al. Governing and delivering a biome-wide restoration initiative: the case of atlantic forest restoration pact in brazil. Forests. 2014;5:2212-29.

48. Ankersen TT, Regan KE, Mack SA. Towards a bioregional approach to tropical forest conservation: Costa Rica's greater osa bioregion. Futures. 2006;38:406-31.
49. Rouget M, Cowling RM, Lombard AT, Knight AT, Kerley GIH. Designing large-scale conservation corridors for pattern and process diseño de corredores de conservación de gran escala para patrones y procesos. Conserv Biol. 2006;20:549-61.

50. Crow TR. What Can Landscape Ecology Contribute to Forest Landscape Restoration? In: Stanturf J, Lamb D, Madsen P, editors. Forest Landscape Restoration. World Forests: Springer Netherlands; 2012. p. 25-37.

51. Noss RF, Dobson AP, Baldwin R, Beier P, Davis CR, Dellasala DA, et al. Bolder thinking for conservation. Conserv Biol. 2012;26:1-4.

52. Gillson L, Dawson TP, Jack S, McGeoch MA. Accommodating climate change contingencies in conservation strategy. Trends Ecol Evol. 2013;28:135-42.

53. Menz MHM, Dixon KW, Hobbs RJ. Hurdles and opportunities for landscape-scale restoration. Science. 2013;339:526-7.

54. Chazdon RL, Brancalion PHS, Lamb D, Laestadius L, Calmon M, Kumar C. A policy-driven knowledge agenda for global forest and landscape restoration. Forest Landsc Restor. 2012;15:25-37.

55. Chazdon RL, Brancalion PHS, Lamb D, Laestadius L, Calmon M, Kumar C. A Policy-Driven Knowledge Agenda for Global Forest and Landscape Restoration. Conservation Letters. 2015;Online Early.

56. Kormann U, Scherber C, Tscharntke T, Klein N, Larbig M, Valente $\mathrm{JJ}$ et al. Corridors restore animal-mediated pollination in fragmented tropical forest landscapes. Proceedings of the Royal Society of London B: Biological Sciences. 2016;283:doi: 10. 1098/rspb.2015.347.

57. Brosi BJ, Armsworth PR, Daily GC. Optimal design of agricultural landscapes for pollination services. Conserv Lett. 2008;1:27-36.

58. Lindenmayer D, Hobbs RJ, Montague-Drake R, Alexandra J, Bennett A, Burgman M, et al. A checklist for ecological management of landscapes for conservation. Ecol Lett. 2008;11:78-91.

59. Smith WP. Sentinels of ecological processes: the case of the northern flying squirrel. Bioscience. 2012;62:950-61.

60. Lonsdorf E, Kremen C, Ricketts T, Winfree R, Williams N, Greenleaf S. Modelling pollination services across agricultural landscapes. Ann Bot. 2009;103:1589-600.

61. Shafer CL. National park and reserve planning to protect biological diversity: some basic elements. Landsc Urban Plan. 1999;44:12353 .

62. Lamberson RH, Noon BR, Voss C, McKelvey KS. Reserve design for territorial species - the effects of patch size and spacing on the viability of the northern spotted owl. Conserv Biol. 1994;8:185-95.

63. Damschen EI, Haddad NM, Orrock JL, Tewksbury JJ, Levey DJ. Corridors increase plant species richness at large scales. Science. 2006;313:1284-6.

64. Gilbert F, Gonzalez A, Evans-Freke I. Corridors maintain species richness in the fragmented landscapes of a microecosystem. Proc $\mathrm{R}$ Soc B Biol Sci. 1998;265:577-82.

65. Laurance WF, Camargo JLC, Luizao RCC, Laurance SG, Pimm SL, Bruna EM, et al. The fate of Amazonian forest fragments: a 32-year investigation. Biol Conserv. 2011;144:56-67.

66. Shiels AB, González G. Tropical forest responses to large-scale experiments. Bioscience. 2015;65:839-40.

67. Hurlbert SH. Pseudoreplication and the design of ecological field experiments. Ecol Monogr. 1984;54:187-211.

68. Betts MG, Forbes GJ, Diamond AW, Taylor PD. Independent effects of fragmentation on forest songbirds: an organism-based approach. Ecol Appl. 2006;16:1076-89.

69. Hadley AS, Frey SJK, Robinson WD, Kress WJ, Betts MG Tropical forest fragmentation limits pollination of a keystone understory herb. Ecology. 2014;95:2202-12.

70. Platt JR. Strong inference. Science. 1964;146:347-53.

71. Smith AC, Koper N, Francis CM, Fahrig L. Confronting collinearity: comparing methods for disentangling the effects of habitat loss and fragmentation. Landsc Ecol. 2009;24:1271-85. 
72. Trzcinski MK, Fahrig L, Merriam G. Independent effects of forest cover and fragmentation on the distribution of forest breeding birds. Ecol Appl. 1999;9:586-93.

73. Ruffell J, Banks-Leite C, Didham RK. Accounting for the causal basis of collinearity when measuring the effects of habitat loss versus habitat fragmentation. Oikos. 2016;125:117-25.

74. Freckleton RP. On the misuse of residuals in ecology: regression of residuals vs. multiple regression. J Anim Ecol. 2002;71:542-5.

75. Schmeller DS, Evans D, Lin Y-P, Henle K. The national responsibility approach to setting conservation priorities-Recommendations for its use. J Nat Conserv. 2014;22:349-57.

76. Jones J. Habitat selection studies in avian ecology: a critical review. Auk. 2001;118:557-62.

77. Hansen MC, Potapov PV, Moore R, Hancher M, Turubanova SA, Tyukavina A, et al. High-resolution global maps of 21st-century forest cover change. Science. 2013;342:850-3.

78. Betts MG, Fahrig L, Hadley AS, Halstead KE, Bowman J, Robinson WD, et al. A species-centered approach for uncovering generalities in organism responses to habitat loss and fragmentation. Ecography. 2014;37:517-27.

79. Forister ML, McCall AC, Sanders NJ, Fordyce JA, Thorne JH, O'Brien J, et al. Compounded effects of climate change and habitat alteration shift patterns of butterfly diversity. Proc Natl Acad Sci U S A. 2010;107:2088-92.

80. Burgi M, Hersperger AM, Schneeberger N. Driving forces of landscape change - current and new directions. Landsc Ecol. 2004;19: 857-68.

81. Comfort EJ, Clark DA, Anthony RG, Bailey J, Betts MG. Quantifying edges as gradients at multiple scales improves habitat selection models for northern spotted owl. Landscape Ecology. 2016; Online Early:1-14.

82. Almeida-Gomes M, Prevedello JA, Crouzeilles R. The use of native vegetation as a proxy for habitat may overestimate habitat availability in fragmented landscapes. Landscape Ecology. 20151-9.

83. Shirley SM, Yang Z, Hutchinson RA, Alexander JD, McGarigal K, Betts MG. Species distribution modelling for the people: unclassified landsat TM imagery predicts bird occurrence at fine resolutions. Divers Distrib. 2013;19:855-66.

84. Calabrese JM, Certain G, Kraan C, Dormann CF. Stacking species distribution models and adjusting bias by linking them to macroecological models. Glob Ecol Biogeogr. 2014;23:99-112.

85. Halstead K, Alexander JD, Stephens J, Betts MG. Fragmentation outweighs landscape composition as a predictor of avian diversity in a temperate forest system. In Prep.

86. Moilanen A, Hanski I. On the use of connectivity measures in spatial ecology. Oikos. 2001;95:147-51.

87. Norris DR, Stutchbury BJM. Extraterritorial movements of a forest songbird in a fragmented landscape. Conserv Biol. 2001;15:72936.

88. Dunning JB, Danielson BJ, Pulliam HR. Ecological processes that affect populations in complex landscapes. Oikos. 1992;65:169-75.

89. Andren $H$. Effects of habitat fragmentation on birds and mammals in landscapes with different proportions of suitable habitat - a review. Oikos. 1994;71:355-66.

90. Fahrig L. Effect of habitat fragmentation on the extinction threshold: a synthesis. Ecol Appl. 2002;12:346-53.

91. Fahrig L. When does fragmentation of breeding habitat affect population survival? Ecol Model. 1998;105:273-92.

92. Zuckerberg B, Porter WF. Thresholds in the long-term responses of breeding birds to forest cover and fragmentation. Biol Conserv. 2010;143:952-62.

93. Betts MG, Hagar JC, Rivers JW, Alexander JD, McGarigal K, McComb BC. Thresholds in forest bird occurrence as a function of the amount of early-seral broadleaf forest at landscape scales. Ecol Appl. 2010;20:2116-30.

94. Pfeifer M, Lefebvre V, Gardner TA, Arroyo-Rodriguez V, Baeten L, Banks-Leite C, et al. BIOFRAG - a new database for analyzing BIOdiversity responses to forest FRAGmentation. Ecol Evol. 2014;4:1524-37.

95. Hudson LN, Newbold T, Contu S, Hill SLL, Lysenko I, De Palma A, et al. The PREDICTS database: a global database of how local terrestrial biodiversity responds to human impacts. Ecol Evol. 2014;4:4701-35. 